\title{
Predictors and prevalence of obstructive sleep apnoea and snoring in 1001 middle aged men
}

\author{
J R Stradling, J H Crosby
}

\begin{abstract}
One thousand and one men, aged 35-65 years, were identified from the age-sex register of one group general practice. Over four years 900 men were visited at home and asked questions about symptoms potentially related to sleep apnoea and snoring. Height, weight, neck circumference, resting arterial oxygen saturation $\left(\mathrm{SaO}_{2}\right)$, and spirometric values were also determined. All night oximetry was then performed at home and the tracing analysed for the number of dips in $\mathrm{SaO}_{2}$ of more than $4 \%$. Subjects with more than five dips of $4 \% \mathrm{SaO}_{2}$ or more per hour were invited for sleep laboratory polysomnography. Seventeen per cent of the men admitted to snoring "often." Multiple linear regression techniques identified and ranked neck circumference $\left(r^{2}=7 \cdot 2 \%\right)$, cigarette consumption $\left(r^{2}=3.4 \%\right)$, and nasal stufiness $\left(r^{2}=2 \%\right)$ as the only significant independent predictors of snoring. Together these account for at least a sixfold variation in the likelihood of being an "often" snorer. Forty six subjects $(5 \%)$ had $>4 \% \mathrm{SaO}_{2}$ dip rates of over five an hour and 31 of these had full sleep studies. Three subjects had clinically obvious and severe symptomatic obstructive sleep apnoea, giving a prevalence of three per 1001 men $(0.3 \% ; 95 \%$ confidence interval $0.07-0.9 \%)$. Eighteen men had obstructive sleep apnoea only when supine and in 10 the cause of the $\mathrm{SaO}_{2}$ dipping on the original home tracing was not elucidated. The $>4 \% \mathrm{SaO}_{2}$ dip rates correlated with the history of snoring. Multiple linear regression techniques identified and ranked neck circumference $\left(\mathbf{r}^{2}=7.9 \%\right)$, alcohol consumption $\left(r^{2}=3 \cdot 7 \%\right)$, age $\left(r^{2}=1 \%\right)$ and obesity $\left(r^{2}=1 \%\right)$ as the only significant independent predictors of the rate of overnight hypoxic dipping. This study shows that snoring in this randomly selected population correlates best with neck size, smoking, and nasal stuffiness. Obstructive sleep apnoea, defined by nocturnal hypoxaemia, correlates best with neck size and alcohol, and less so with age and general obesity.
\end{abstract}

Churchill Hospital, Oxford, OX3 7LJ

J R Stradling

J H Crosby

Reprint requests to:

Dr Stradling

Accepted 14 November 1990
Obstructive sleep apnoea has been recognised increasingly as an important medical condi- tion producing severe morbidity and appreciable excess mortality. ${ }^{1-3}$ Patients and doctors often fail to link the twin symptoms of loud snoring and excessive daytime sleepiness to this specific diagnosis. This means that many cases go undiagnosed and the opportunity to provide effective treatment is then lost. One major factor limiting the committal of educational and financial resources to this problem is the absence of any comprehensive data on the prevalence of this condition. This study describes the findings of a prospective survey of sleep and breathing disorders in a randomly selected group of 1001 middle aged men drawn from the age-sex register of a single group general practice. Some early results from this study, concerning the association of sleep apnoea with blood pressure, have already been published. ${ }^{4}$

\section{Methods}

SUBJECTS

One group general practice (four partners) serving the town of Wheatley $(8 \mathrm{~km}$ east of Oxford) allowed us to use their age and sex register to identify a total of 1596 men aged 35-65 years. No one was excluded from the study for any reason other than unavailability (see later) or refusal to participate. The order in which subjects were then selected for study was randomised according to year of birth. Each subject received a letter of explanation, signed by his general practitioner, followed by a telephone call or letter from one of us (JC).

\section{TECHNIQUES}

A questionnaire was administered to each subject asking about a range of factors thought to be potential causes of sleep apnoea and snoring. We asked about alcohol consumption (categories 1-4: $<10 \mathrm{~g} /$ day, 10-39 g/day, 40$70 \mathrm{~g} /$ day, $>70 \mathrm{~g} /$ day), cigarette consumption, (categories 1-4: nil, 1-5/day, 6-15/day, >15/ day), nasal stuffiness (for example, hayfever), previous nasal damage or surgery, previous adenotonsillectomy, use of sedative or hypnotic drugs, and the regular use of any other drugs. In addition, the subjects were asked about any snoring, and we recorded whether the subject's wife was present at the interview and the nature of his current occupation.

At the time of interview the following information was also recorded: age, weight (portable scales: SECA, Germany; calibration checked monthly), height (steel rule), neck circumference (at the level of the cricothyroid 
membrane), lung spirometric values (forced expiratory volume in one second $\left(\mathrm{FEV}_{1}\right)$ and forced vital capacity (FVC): turbine spirometer-calibration was checked weekly), Micro Medical Instruments, Rochester, Kent, ${ }^{5}$ and resting arterial oxygen saturation $\left(\mathrm{SaO}_{2}\right.$ : Ohmeda 3700 pulse oximeter). ${ }^{6}$ The same instruments were used throughout. The neck circumference was found to be minimally dependent on height in an interim analysis of 300 subjects (neck circumference $(\mathrm{cm})=5.5 \times$ height $(\mathrm{m})+31 ; \mathrm{r}=0.16)$, and was therefore corrected for height and expressed as a percentage predicted value (the findings from a later analysis including all 900 subjects did not materially alter the initial relationship).

Overnight oxygenation (eight hours) was measured in the subject's home with an Ohmeda Biox 3700 pulse oximeter (version J) with the flexible finger probe. ${ }^{6}$ The machine's internal memory stores a two digit value at the end of every 12 seconds, representing the lowest percentage $\mathrm{SaO}_{2}$ detected during the preceding 12 seconds. Dips in $\mathrm{SaO}_{2}$ are accurately recorded but recoveries of $\mathrm{SaO}_{2}$ between short dips will be slightly underestimated. ${ }^{6} \mathrm{Up}$ to a maximum of eight hours of stored data (2400 points) were transferred and analysed by computer (BBC B). The overnight median and the number of dips in $\mathrm{SaO}_{2}$ of more than $4 \%$ were calculated and expressed per hour of tracing. The exact algorithm for dip detection has been described elsewhere. ${ }^{4}$

Full sleep studies were performed on a subset of subjects with abnormal $\mathrm{SaO}_{2}$ tracings (see below) in a hospital sleep laboratory. The electroencephalogram, electro-oculogram, electromyogram (submental), oximetric data, ribcage and abdominal movements (respiratory inductance plethysomography, Ambulatory Monitoring Inc or Vitalog), and oronasal flow were recorded on an eight channel portable tape recording system (MPA 9000, Oxford Medical). In addition, simultaneous eight hour video recordings with sound were performed to record posture and confirm the polysomonographic findings. The MPA 9000 recordings were processed automatically for sleep staging according to standard criteria, ${ }^{7}$ and important or abnormal areas verified by manual scoring. Five of the 31 subjects undergoing laboratory sleep studies consented only to video recordings with oximetry; these were carefully reviewed to establish the cause of the hypoxic dipping.

\section{PROTOCOL}

After the preliminary letter and telephone call the subjects were all visited at home by JC over the course of four years. The study was explained and the questionnaire completed. If the subject's wife was present, they were allowed to discuss the answers before the replies were noted. The various measurements were then made. The subjects were shown how to use the oximeter and given the flexible probe, which was ready to slip on to the finger, using the disposable sticky tapes supplied by Ohmeda. The subjects applied the probe and switched on the machine when retiring to bed, and switched it off on waking next morning, ready for collection and return to the hospital. The subjects were also asked if they had had their usual amount of alcohol and whether they had slept "more than normally," "normally," "slightly less than normal," or "much less than normal."

This protocol was approved by the Oxford ethics committee.

\section{STATISTICS}

All data were entered on to the Oxford University Vax computer by an experienced keyboard operator, checked, and analysed by the SAS statistical package. ${ }^{8}$ The $95 \%$ confidence intervals $(\mathrm{CI})$ of the prevalence figures were estimated according to Gardner and Altman on the assumption of a normal distribution. The interrelations among the data were first examined by Pearson's correlation coefficient, analysis of variance, or the $\chi^{2}$ test as appropriate. The data were then examined together by multiple linear regression techniques with the rate of $>4 \% \mathrm{SaO}_{2}$ dipping as the dependent variable. The stepwise procedure (with $\mathrm{p}<0.15$ as the significance level for entry or retention) was used initially, similar results being obtained by either the backward or the forward method for entering variables. ${ }^{10}$ For dealing correctly with discontinuous variables (for example, cigarette and alcohol consumption) the general linear models procedure was also used with the classes option, ${ }^{8}$ and the variables entered in the order indicated by the stepwise model. All these analyses gave the same $r^{2}$ values for each variable, and the $p$ values reported here are from the general linear models procedure. These analyses were carried out on the whole population with complete data, a subset where the wife was present at interview ( $n=468$ ), and a subset not currently taking any medicines $(\mathrm{n}=676)$

\section{Results}

Of the 1596 men aged 35-65 years on the agesex register, 595 could not be contacted. Most of these had left the practice area or died and the cards had not been removed from the register box. Forty six did not answer two letters, never answered or had no telephone, and did not answer a knock at their door; some of these men were subsequently discovered to be spending most of their time abroad. One thousand and one were thus contacted, of whom $900(90 \%)$ agreed to be seen and 893 agreed to overnight oximetry. Only $18(2 \%)$ of these 893 subjects said that they slept "much less than normal," the rest sleeping "slightly less," "the same as," or "more than" normal. Seventy one $(8 \%)$, however, said they had "less than" their usual amount of alcohol. The average length of the $\mathrm{SaO}_{2}$ tracings obtained was 6.92 (SD 0.11) hours.

\section{SNORING}

The prevalence of snoring in 890 men is shown in figure 1. The prevalence of snoring "often" 
$\%$ of subjects

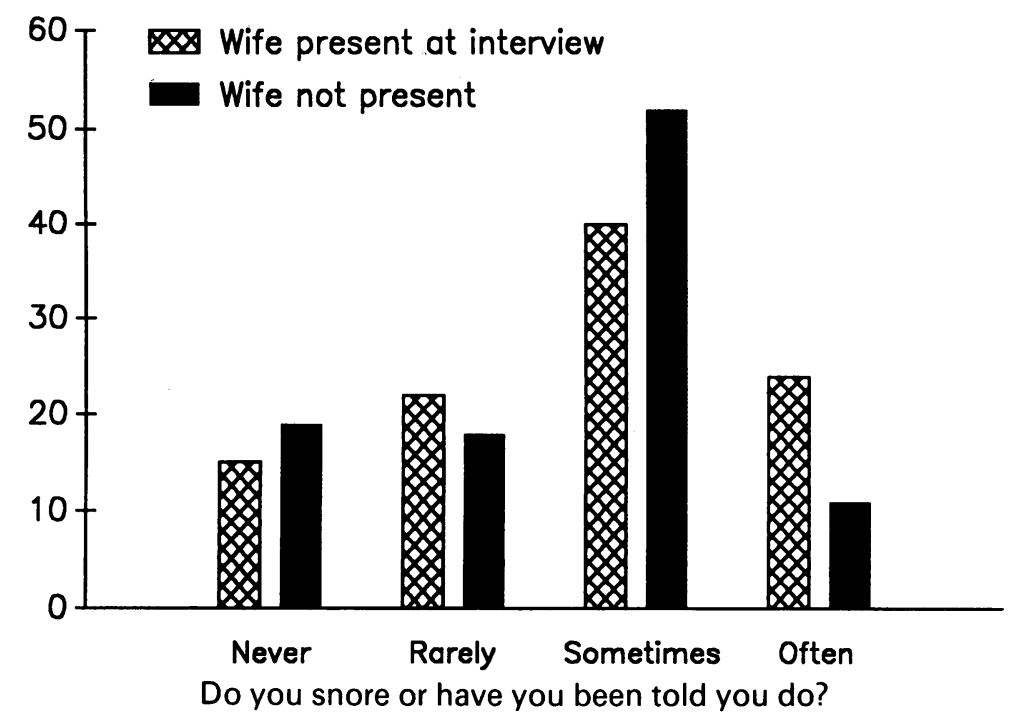

Figure 1 Prevalence of snoring in 890 men aged 35-65 years divided according to whether their wives were present $(n=468)$ during administration of the questionnaire or not $(n=422)$. $\mathrm{p}<0.0001)$, obesity $\left(\mathrm{r}^{2}=6 \%, \mathrm{p}<0.0001\right)$, and age $\left.r^{2}=2 \%, p<0.0001\right)$.

In a multiple linear regression model only $\%$ predicted neck circumference $\left(\mathrm{r}^{2}=7 \cdot 2 \%\right.$, $\mathrm{p}<0.0001)$, cigarette consumption $\left(r^{2}=3.4 \%, p=0.0005\right)$, and nasal stuffiness $\left(r^{2}=2.0 \%, p=0.01\right)$ contributed significantly to the snoring. A subject in the top quartile of neck circumference, smoking over 15 cigarettes a day, and complaining of a stuffy or blocked up nose was 6.4 times more likely to be an "often" snorer than was a non-smoker in the bottom quartile for neck circumference who never experienced nasal stuffiness $(40 \cdot 7 \%$ $v 6.4 \%$ ).

Analysis of the subset where the wife was present at inteview did not alter these patterns of significance.

\section{SLEEP HYPOXAEMIA}

Of the 893 subjects having overnight oximetry, $45(5 \%)$ had $>4 \% \mathrm{SaO}_{2}$ dip rates of more than five an hour and 31 of these consented to full sleep studies. Three subjects had severe obstructive sleep apnoea in any posture with $>4 \% \mathrm{SaO}_{2}$ dip rates of 85,47 , and 22 per hour of study. These three subjects were clearly symptomatic and had been for several years. The prevalence of severe obstructive sleep apnoea in our study (three out of 1000) was therefore $0.3 \%$ (95\% CI 0.07-0.9\%). Eighteen of the remaining subjects studied in the sleep laboratory had obstructive sleep apnoea only when asleep in the supine posture. Unfortunately the other 10 subjects slept too badly (under two hours' total sleep or no rapid eye movement sleep), or never supine, to allow the cause of the $\mathrm{SaO}_{2}$ dipping in the original home study to be categorised confidently. None of the 14 subjects who refused polysomnography, or of the 10 who slept badly in the laboratory, had such pronounced falls in $\mathrm{SaO}_{2}$ in the home oximetry tracings as the three subjects with obstructive sleep apnoea. Their mean $>4 \%$ $\mathrm{SaO}_{2}$ dip rate from the home oximeter tracings was no different from that of the group who had adequate polysomnography studies. In the 18

Table 1 Overall results from the questionnaire for the discontinuous variables

\begin{tabular}{|c|c|c|c|c|c|}
\hline Alcohol consumption & $\begin{array}{l}\text { g/day: } \\
\text { n } \\
\%\end{array}$ & $\begin{array}{c}<10 \\
447 \\
49 \cdot 7\end{array}$ & $\begin{array}{c}10-39 \\
324 \\
36 \cdot 0\end{array}$ & $\begin{array}{c}40-70 \\
112 \\
12 \cdot 5\end{array}$ & $\begin{array}{c}>70 \\
16 \\
1.8\end{array}$ \\
\hline Cigarette consumption & $\begin{array}{l}\text { No/day: } \\
\mathrm{n} \\
\%\end{array}$ & $\begin{array}{c}0 \\
632 \\
70 \cdot 2\end{array}$ & $\begin{array}{c}1-5 \\
84 \\
9 \cdot 3\end{array}$ & $\begin{array}{c}6-15 \\
80 \\
8 \cdot 9\end{array}$ & $\begin{array}{c}>15 \\
104 \\
11 \cdot 6\end{array}$ \\
\hline Nasal stuffiness & $\begin{array}{l}\text { Grade: } \\
\mathbf{n} \\
\%\end{array}$ & $\begin{array}{c}\text { Never } \\
449 \\
49.9\end{array}$ & $\begin{array}{l}\text { Rarely } \\
127 \\
14 \cdot 1\end{array}$ & $\begin{array}{l}\text { Sometimes } \\
230 \\
25 \cdot 6\end{array}$ & $\begin{array}{l}\text { Often } \\
94 \\
10 \cdot 4\end{array}$ \\
\hline Previous nasal damage or surgery & $\begin{array}{l}\text { Grade: } \\
\text { n } \\
\%\end{array}$ & $\begin{array}{l}\text { No } \\
632 \\
70 \cdot 2\end{array}$ & $\begin{array}{l}\text { Damaged } \\
188 \\
20 \cdot 9\end{array}$ & $\begin{array}{c}\text { Surgery } \\
49 \\
5.4\end{array}$ & $\begin{array}{l}\text { Both } \\
31 \\
3 \cdot 4\end{array}$ \\
\hline Previous adenotonsillectomy & $\begin{array}{l}\text { Answer: } \\
\mathrm{n} \\
\%\end{array}$ & $\begin{array}{l}\text { Yes } \\
331 \\
36 \cdot 7\end{array}$ & $\begin{array}{l}\text { No } \\
536 \\
59 \cdot 6\end{array}$ & $\begin{array}{l}\text { (Not known) } \\
33 \\
3.6\end{array}$ & \\
\hline Sedatives at night & $\begin{array}{l}\text { Answer: } \\
\mathrm{n} \\
\%\end{array}$ & $\begin{array}{l}\text { Never } \\
844 \\
94 \cdot 1\end{array}$ & $\begin{array}{c}\text { Rarely } \\
23 \\
2 \cdot 6\end{array}$ & $\begin{array}{l}\text { Sometimes } \\
17 \\
1.9\end{array}$ & $\begin{array}{l}\text { Often } \\
13 \\
1.4\end{array}$ \\
\hline Other regular drugs & $\begin{array}{l}\text { Answer: } \\
\text { n } \\
\%\end{array}$ & $\begin{array}{l}\text { Yes } \\
224 \\
24 \cdot 9\end{array}$ & $\begin{array}{l}\text { No } \\
676 \\
75 \cdot 1\end{array}$ & & \\
\hline Do you snore or have you been told you do? & $\begin{array}{l}\text { Grade: } \\
\mathbf{n} \\
\%\end{array}$ & $\begin{array}{c}\text { Never } \\
147 \\
16.5\end{array}$ & $\begin{array}{l}\text { Rarely } \\
174 \\
19 \cdot 6\end{array}$ & $\begin{array}{l}\text { Sometimes } \\
419 \\
47 \cdot 1\end{array}$ & $\begin{array}{c}\text { Often } \\
150 \\
16.9\end{array}$ \\
\hline
\end{tabular}


Table 2 Overall results for the continuous variables

\begin{tabular}{|c|c|c|c|c|c|}
\hline & Mean & $S D$ & Median & $5-95 \%$ range & $0-100 \%$ range \\
\hline Age (y) & $48 \cdot 2$ & $8 \cdot 6$ & 48 & $35-62$ & $35-65$ \\
\hline Height (m) & 1.76 & 0.07 & $1 \cdot 77$ & $1 \cdot 65-1 \cdot 87$ & $1 \cdot 48-2 \cdot 00$ \\
\hline Weight (kg) & $79 \cdot 1$ & $11 \cdot 4$ & 78 & $63-100$ & $53-134$ \\
\hline Body mass index $\left(\mathrm{wt} / \mathrm{ht}^{2}\right)$ & $25 \cdot 3$ & $3 \cdot 2$ & $24 \cdot 9$ & $20 \cdot 9-30 \cdot 8$ & $15 \cdot 3-45 \cdot 8$ \\
\hline Neck circumference $(\mathrm{cm})$ & $40 \cdot 2$ & $2 \cdot 4$ & 40 & $37-44 \cdot 5$ & $34-51$ \\
\hline$\%$ predicted normal neck circumference & $98 \cdot 8$ & 5.9 & $98 \cdot 4$ & $90 \cdot 3-108$ & $84 \cdot 4-126$ \\
\hline $\mathrm{FEV}_{1}(\%$ predicted normal $)$ & $90 \cdot 9$ & $16 \cdot 8$ & 93 & $60 \cdot 9-115$ & $17-135$ \\
\hline $\mathrm{FEV}_{1} / \mathrm{VC}$ ratio $(\%)$ & $76 \cdot 3$ & $9 \cdot 7$ & 78 & $59-90$ & $30-98$ \\
\hline Resting awake $\mathrm{SaO}_{2}(\%)$ & $95 \cdot 9$ & $1 \cdot 3$ & 96 & $94-98$ & $87-99$ \\
\hline$>4 \% \mathrm{SaO}_{2} \mathrm{dips} / \mathrm{h}$ & 1.85 & $3 \cdot 54$ & $1 \cdot 14$ & $0 \cdot 25-5 \cdot 12$ & $0-85$ \\
\hline Median overnight $\mathrm{SaO}_{2}(\%)$ & $94 \cdot 3$ & $1 \cdot 6$ & 94 & $92-96$ & $77-98$ \\
\hline
\end{tabular}

*See under "techniques" for derivation.

$\mathrm{FEV}_{1}$ - force expiratory volume in one second; $\mathrm{VC}$ - vital capacity; $\mathrm{SaO}_{2}$ - arterial oxygen saturation.

subjects with "supine only" obstructive sleep apnoea the $>4 \% \mathrm{SaO}_{2}$ dip rate over the whole night would depend critically on the proportion of sleeping time spent supine. ${ }^{112}$ Figure 2 shows the overall distribution of $>4 \% \mathrm{SaO}_{2}$ dip rates for the 893 subjects and indicates a smooth distribution with no suggestion of bimodality. As would have been expected, the $>4 \% \mathrm{SaO}_{2}$ dip rates correlated with the history of snoring, mean values being $1.2,1.3,1.8$ and $3 \cdot 1$ hour in the "never," "rarely," "sometimes," and "often" snoring groups $(\mathrm{p}<0.0001)$.

Examination of the continuous variables (table 2) with simple linear regression showed that the frequency of $>4 \% \quad \mathrm{SaO}_{2}$ dips correlated with $\%$ predicted normal neck circumference $(r=0.28, p<0.0001)$, obesity $(\mathrm{r}=0.26, \quad \mathrm{p}<0.0001), \quad$ age $\quad(\mathrm{r}=0.15$, $\mathrm{p}<0.0001), \quad$ awake $\mathrm{SaO}_{2} \quad(\mathrm{r}=0.12$, $\mathrm{p}=0.0002)$, and $\%$ predicted $\mathrm{FEV}_{1}$ $(\mathrm{r}=-0 \cdot 10, \mathrm{p}=0 \cdot 004)$. Examination of the discontinuous variables (table 1) with analysis of variance showed significant associations only between $>4 \% \mathrm{SaO}_{2}$ dip rates and alcohol consumption $\left(\mathrm{r}^{2}=4 \%, \mathrm{p}<0.0001\right)$ and $\mathrm{a}$ history of nasal stuffiness $\left(r^{2}=1 \%, p=0.02\right)$. In a multiple linear regression model only four of these five continuous and two discontinuous variables continued to show a significant

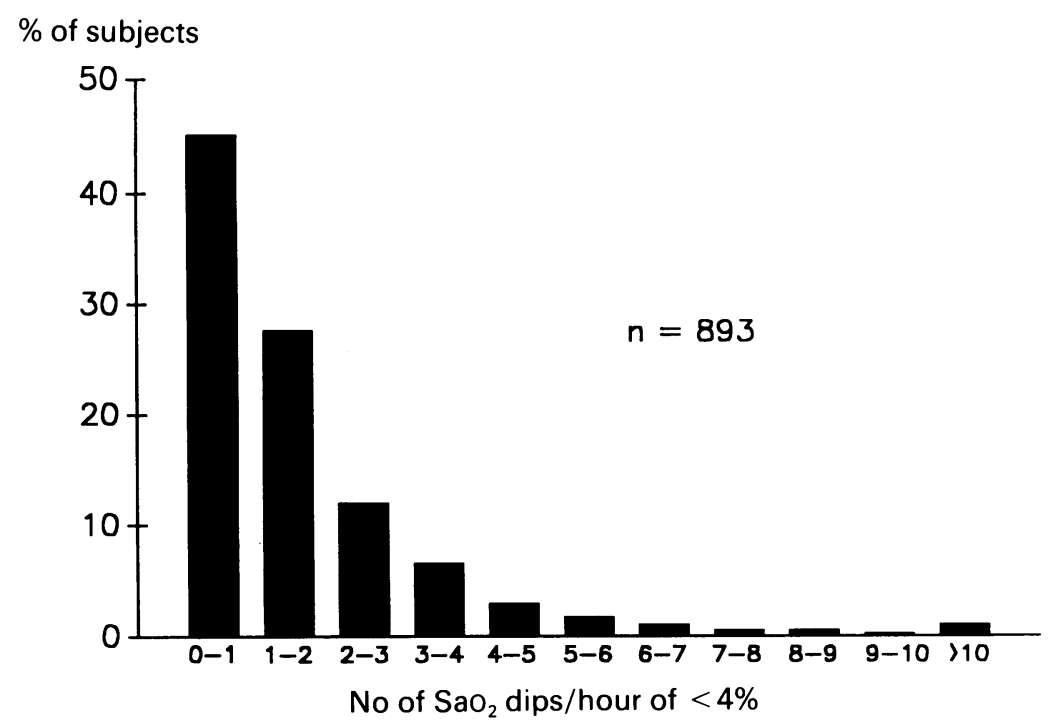

Figure 2 Prevalence distribution of dips of more than $4 \%$ in arterial oxygen saturation $\left(>4 \% \mathrm{SaO}_{2}\right.$ dips) per hour in 893 men aged 35-65 years. association with the frequency of $>4 \% \mathrm{SaO}_{2}$ dips and these variables together explained $13.6 \%$ of the variance. Of greatest significance was $\%$ predicted normal neck circumference $\left(\mathrm{r}^{2}=7.9 \%, \mathrm{p}<0.0001\right)$ followed by alcohol consumption $\left(r^{2}=3.7 \%, p<0.0001\right)$, age $\left(r^{2}=1 \%, p=0.009\right)$, and obesity $\left(r^{2}=1 \%\right.$, $\mathrm{p}=0.01)$. Presumably the other variables were only indirectly related through these primary four, and only neck circumference and alcohol consumption appear to have an important effect on the frequency of nocturnal hypoxaemic dips. Analysis of the subset of subjects not taking any drugs did not significantly alter these interrelationships between variables.

\section{Discussion}

The subjects approached for our screening study were the total contactable male population (aged 35-65 years) on the practice's register, and $90 \%$ agreed to be studied. Thus, unless the $10 \%$ who refused were different from the group as a whole, our population should be representative of the men of this age group in that community. We persuaded over half the subjects who refused to participate in an overnight sleep study to provide information on weight, height, and collar size and on whether they were taking any drugs. These 57 subjects did not differ from the study population for any of these variables, and in particular the mean collar size was similar to the study population's mean neck circumference $(98.0$ v $98.8 \%$ predicted normal). Thus in terms of the variable found to be most predictive of sleep hypoxaemia subjects who refused to participate did not differ from those who did. Although the study group was not representative of the British population as a whole (for example, the social class distribution revealed $54 \%$ were from social classes I and II and $14 \%$ from classes IV and V, compared with $32 \%$ and $21 \%$ in England as a whole), their degree of obesity was the same. The average obesity index of our population was 25.3 compared with 25.2 for an age matched British male population. ${ }^{13}$ Thus there were no differences in one of the major predictive variables, obesity, that could have biased our data.

The choice of home oximetry to identify cases of sleep apnoea was a compromise. Full 
polysomnography in a sleep laboratory would have been too expensive and reduced the acceptance rate of our subjects dramatically. Several groups have shown very close approximation between a fall in $\mathrm{SaO}_{2}$ of over $4 \%$ and apnoea of more than 10 seconds (the conventional definition). ${ }^{14-18} \mathrm{We}$ accept that a few subjects with early sleep apnoea may not allow their $\mathrm{SaO}_{2}$ to fall by $4 \%$ before waking up. In our clinical experience this is very uncommon but would mean that we may have slightly underestimated the degree of sleep related breathing irregularities in this group. We will also not have recognised loud snorers with no hypoxaemia, but whether this group has a higher morbidity than non-snorers is not yet known. ${ }^{41920}$ In all cases where verification of recurrent dips in $\mathrm{SaO}_{2}$ of over $4 \%$ was possible by video recordings and polysomnography the cause was obstructive sleep apnoea with variable amounts of associated snoring. In the population as a whole, as would be expected, there was a very high association between snoring and $>4 \% \mathrm{SaO}_{2}$ dip rate. Home oximetry is unlikely to have appreciably disturbed sleep as only $2 \%$ said they had slept "much less" than normal. In 35 of the subjects a wrist activity monitor was also used to verify sleep $^{21}$ and these recordings showed long periods of sleep with usual numbers of arousals, similar to those of subjects not having oximetry. Thus we are confident that oximetry recordings alone are an adequate epidemiological tool for identifying sleep apnoea and will tend to err on the side of underrecognition rather than overrecognition.

The prevalence of snoring and possible causative factors identified in this study are similar to those found by others. ${ }^{1820223}$ These, however, are the first data to show that the link between obesity and snoring is probably due to increased neck circumference rather than general obesity. The relation between obesity and $\%$ predicted normal neck circumference is, of course, very strong $(r=0.75)$; but it is possible to be of normal weight and have a large neck, and vice versa. The greater importance of neck obesity than of general obesity in producing upper airway incompetence during sleep has been documented in patients with sleep apnoea, ${ }^{24}{ }^{25}$ and the mechanism is presumably external compression of the pharynx by superficially located fat masses. ${ }^{2627}$ The prevalence of severe symptomatic obstructive sleep apnoea in our population of men aged 35-65 years was $0.3 \%$. Two of the three subjects are now having nasal continuous positive airway pressure with total relief of symptoms, and the third, though very sleepy, has retired from work early and is not sufficiently concerned about his symptoms to contemplate treatment, other than weight loss. The prevalence of moderate sleep apnoea in our group, defined on the basis of oxygen desaturation, depends entirely on the criteria chosen. Some individuals will also vary with respect to any particular chosen level, depending on the proportion of the study night spent supine. ${ }^{11}$ Figure 2 makes it clear that a cut off at either five or ten $>4 \% \mathrm{SaO}_{2}$ dips/hour would be an arbitrary choice. If a $>4 \% \mathrm{SaO}_{2}$ dip rate of more than five an hour is chosen then $45 / 1001$ $(4.5 \%)$ were affected; but if a rate of more than ten an hour is chosen then $10 / 1001(1 \%)$ were affected.

In a report to be published elsewhere we found that men with the higher $\mathrm{SaO}_{2}$ dip rates had only minimally increased self reported daytime sleepiness (such that they were more likely to admit to having to pull off the road while driving as a result of drowsiness) and they performed as well as control subjects in a simple test of vigilance (the multiple unprepared reaction time ${ }^{28}$ ). Thus only the three subjects with severe obstructive sleep apnoea were similar to the patients with the classic disorder seen in a sleep clinic and therefore appropriate candidates for nasal continuous positive airway pressure.

Our figures for prevalence are similar to those obtained in other surveys where individuals suspected of having sleep apnoea are identified from initial questionnaires and a sample is then invited for polysomnography. For example, Lavie et ${ }^{29}$ reviewed 1262 questionnaires from a working male population and, on the basis of the answers, selected a sample of 300 from three groups: excessively sleepy, insomniac, and normal. A higher percentage of the excessively sleepy group than of the normal subjects agreed to sleep studies $(80 \% v 19 \%)$; but 11 of the 78 who had laboratory studies had more than 10 episodes of apnoea (of at least 10 seconds each) an hour. Whether these caused arousal or hypoxaemia is not known and probably only six had classical obstructive sleep apnoea. Thus in that study perhaps six out of 300 at most had moderate to severe sleep apnoea. Gislason et $a l^{30}$ reviewed 3100 questionnaires ( $76 \%$ response rate) and selected for further study the 166 who reported the most snoring and sleepiness combined. No attempt to assess prevalence in an apparently symptomless control group was made. Of the 61 who attended for full sleep studies, 10 had more than 10 respiratory events (apnoea or $>4 \%$ $\mathrm{SaO}_{2}$ falls) an hour, and 15 had more than five an hour. If the 10 are regarded as having appreciable sleep apnoea, their prevalence of $10 / 3100$ is similar to our 3/1000. Lugaresi et al ${ }^{181}$ found only two severely affected and symptomatic patients with obstructive sleep apnoea when studying (with polysomnography) $\mathbf{4 0}$ men who snored every night. The 40 men were randomly selected from $119(10 \%)$ who admitted to snoring every night from 1170 men who answered a questionnaire sent initially to 3479 men aged $30-69$ years. Thus about five patients with severe obstructive sleep apnoea would have been expected per 1000 men. They also, however, obtained an overall estimate of about $5 \%$ for men having more than five episodes of apnoea (or $>4 \% \mathrm{SaO}_{2}$ dips) an hour and 2-3\% for those having more than 10 episodes (or $>4 \% \mathrm{SaO}_{2}$ dips) an hour. These figures are remarkably similar to the data we obtained using only the criterion of a $>4 \% \mathrm{SaO}_{2}$ dip with no additional criterion for apnoea.

The prevalence of obstructive sleep apnoea in a particular population would be expected to vary according to the levels of obesity as this 
factor correlates well with the degree of sleep apnoea. For example, the prevalence of obstructive sleep apnoea in the United States should be higher because $5 \%$ of men weigh over $101.6 \mathrm{~kg}$, whereas in the United Kingdom the 95 th centile is $94.4 \mathrm{~kg}$, and only about $2 \%$ of men are over $102 \mathrm{~kg} .{ }^{13}$

The above studies all suffer from potential bias. For example, individuals agreeing to sleep studies may be more likely to be affected or, as happens in clinical practice, some obviously sleepy individuals with obstructive sleep apnoea may deny that they are so. By using a limited sleep study to screen everyone we have avoided these problems of bias.

In our study $13.6 \%$ of the variance in hypoxic dipping during sleep was accounted for by neck circumference and age. The effect of alcohol was interesting and the most likely explanation is that upper airway muscle tone is reduced by even quite small amounts of alcohol. ${ }^{32}{ }^{33}$ The residual effect of obesity, after neck obesity has been taken into account, may be due to the reduced functional residual capacity in the obese and thus smaller lung oxygen stores, causing a faster decline in $\mathrm{SaO}_{2}$ during apnoea. ${ }^{34}$ In a previous study ${ }^{11}$ we found that night to night variation in $>4 \% \mathrm{SaO}_{2}$ dip rate in subjects with mild to moderate obstructive sleep apnoea was considerable, owing to different amounts of time spent supine; this meant that only about half of the variance in $>4 \%$ $\mathrm{SaO}_{2}$ dip rate in our population could be accounted for by other factors, such as neck circumference and age.

A prevalence of $0.3 \%$ of men aged 35-65 years for severe symptomatic sleep apnoea means that each chest physician covering 150000 people (the recommended ratio in Britain) should be looking after about 100 such male patients, the total number of such patients in Britain being about 36000 (95\% CI 8400108000 ). The prevalence in women is probably less, to judge by clinical experience (1:15 in our unit); in children, although obstructive sleep apnoea clearly exists, ${ }^{35}$ the overall prevalence is not known. These data show that severe symptomatic sleep apnoea is likely to be much more common than, for example, sarcoidosis and fibrosing alveolitis combined. ${ }^{36}$ This has important resource implications for those running hospital respiratory medicine services.

This work was supported by the Wellcome Trust. We thank the general practitioners in Wheatley (Drs R Flury, P Isaac, J Hughes, and $L$ Ware) for their cooperation and help, without which this study would not have been possible.

1 Guilleminault C, Tilkian A, Dement WC. The sleep apnea syndromes. Arune Rev Med 1976;27, 65-84.

2 Partinen M, Jamieson A, Guilleminailt C. Long-term outcome for obstructive sleep apnea syndrome patients. Chest 1988;94:1201-4.

3 He J, Kryger MH, Zorick FJ, Conway W, Roth T. Mortality and apnea index in obstructive sleep apnea. Chest 1988;94:9-14.

4 Stradling JR, Crosby JH. Relation between systemic hypertension and sleep hypoxaemia or sporing: analysis in 748 men drawn from general practice. BMJ 1990;300:75-8.
5 Gunawardena KA, Houston K, Smith AP. Evaluation of the turbine pocket spirometer. Thorax 1987;42:689-93.

6 Warley ARH, Stradling JR, Mitchell J. Evaluation of Ohmeda 3700 pulse oximeter. Thorax 1987;42:892-6.

7 Rechtschaffen A, Kales A. A manual of standardised terminology, techniques and scoring system for sleep stages of human subjects. Washington DC: Public Health Service, 1968. (National Institutes of Health publication No 204.)

8 Cody RP, Smith JK. Applied statistics and the SAS programming language. 2nd edn. New York: Elsevier, 1987.

9 Gardner MJ, Altman DG. Statistics with confidence. London: British Medical Journal, 1989:28-9.

10 Pedhazur ET. Multiple regression in behavioural research. 2nd edn. Texas: Holt, Rinehart and Winston, 1982.

11 Stradling J, Mitchell J. Reproducibility of home oximeter tracings. J Amb Monit 1989;2:203-8.

12 Cartwright RD. Effect of sleep position on sleep apnea severity. Sleep 1984;7:110-4.

13 Knight I. The heights and weights of adults in Great Britain. London: HMSO, 1984.

14 Farney RJ, Walker LE, Jensen RL, Walker JM. Ear oximetry to detect apnea and differentiate rapid-eyemovement (REM) and non-REM (NREM) sleep. Chest 1986;89:533-9.

15 Kripke D, Mason W, Bloomquist J, Cobarrubias M, Engler R, Ancoli-Israel S. Relationship of respitrace apneahypopnea counts and $4 \%$ desaturations. Sleep Res 1988;17:208.

16 Gould GA, Whyte KF, Airlie MAA, Rhind GB, Catteral JR, Shapiro CM, Douglas NJ. Criteria for diagnosing abnormal breathing during sleep [abstract]. Thorax 1987;42:722.

17 George CF, Millar TW, Kryger MH. Identification and quantification of apneas by computer-based analysis of oxygen. Am Rev Respir Dis 1988;137:1238-40.

18 Cirignotta F, D'Alessandro R, Partinen M, et al. Prevalence of every night snoring and obstructive sleep apnoeas among 30-69-year-old men in Bologna, Italy. Acta Psychiatr Scand 1989;79:366-72.

19 Stradling JR. Sleep apnoea and hypertension. Thorax 1989;44:984-9.

20 Schmidt-Nowara WW, Coultas DB, Wiggins C, Skipper BE, Samet JM. Snoring in a Hispanic-American population. Risk factors and association with hypertension and other morbidity. Arch Intern Med 1990;150:597-601.

21 Stradling JR, Warley A, Sharpley A. Wrist actigraphic assessment of sleep. Sleep Res 1987;16:586-6.

22 Bloom JW, Kaltenborn WT, Quan SF. Risk factors in a general population for snoring. Importance of cigarette smoking and obesity. Chest 1988;93:678-83.

23 Lugaresi E, Cirignotta F, Coccagna G, Piana C. Some epidemiological data on snoring and cardiocirculatory disturbances. Sleep 1980;3:221-4

24 Davies RJO, Stradling JR. The relationship between neck circumference, radiographic pharyngeal anatomy, and the constructive sleep apnoea syndrome. Eur Respir J 1990;3:509-14.

25 Katz I, Stradling J, Slutsky AS, Zamel N, Hoffstein V. Do patients with sleep apnea have a short fat neck? [abstract] Am Rev Respir Dis 1989;139:A622.

26 Koenig JE, Thach BT. Effects of mass loading on the upper airway. J Appl Physiol 1988;64:2294-9.

27 Koopmann CF, Field RA, Coulthard SW. Sleep apnea syndrome associated with a neck mass. Otolaryngol Head Neck Surg 1981;89:949-52.

28 Wilkinson RT, Houghton D. Field test of arousal: a portable reaction times test with data storage. Human Factors 1982;24:487-93.

29 Lavie P. Incidence of sleep apnea in a presumably healthy working population. Sleep 1983;6:312-8.

30 Gislason T, Almqvist M, Ariksson G, Taube A, Boman G. Prevalence of sleep apnea syndrome among Swedish men-an epidemiological study. J Clin Epidemiol 1988; 41:571-6.

31 Lugaresi E, Cirignotta F, Gerardi R, Montagna P. Snoring and sleep apnea: natural history of heavy snorers disease. In: Guilleminault C, Partinen M, eds. Obstructive sleep apnea syndrome. New York: Raven Press, 1990:25-36.

32 Issa FG, Sullivan CE. Alcohol, snoring and sleep apnea. $J$ Neurol Neurosurg Psychiatry 1982;45:353-9.

33 Bonora M, Shields GI, Knuth SL, Bartlett D, St-John WM Selective depression by ethanol of upper airway respiratory motor activity in cats. Am Rev Respir Dis 1984;130:156-61.

34 Findlay LJ, Ries AL, Tisi GM, et al. Hypoxemia during apnea in normal subjects: mechanisms and impact of lung volume. J Appl Physiol 1983;55:1777-83.

35 Stradling JR, Thomas G, Williams P, Warley ARH, Freeland A. Efiect of adenotonsillectomy on nocturnal Freeland A. Efrect of adenotonsillectomy on nocturnal children. Lancet 1990;335:249-53.

36 Brewis RAL, Gibson GJ, Geddes DM, eds. Respiratory medicine. London: Baillière Tindall, 1990:1088, 1121 